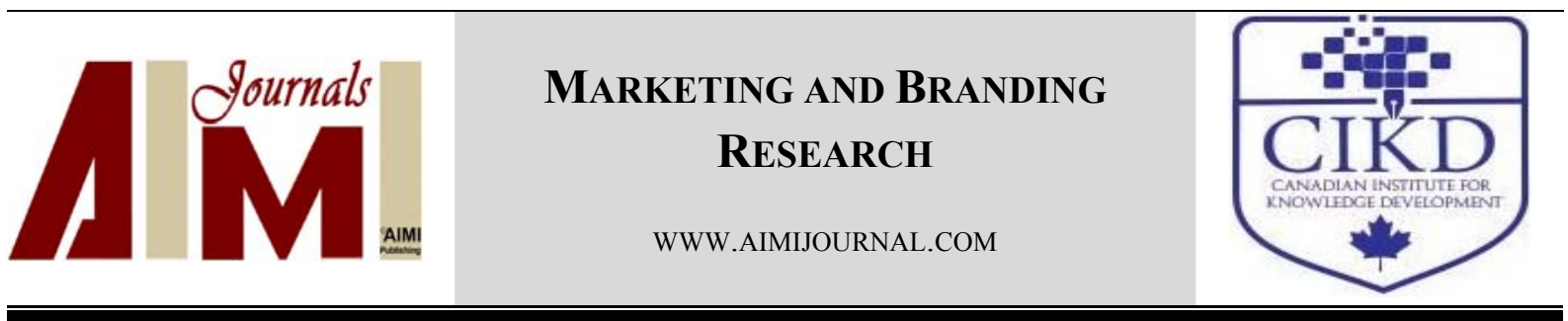

\title{
Air Transport - A Source of Competitive Advantages of the Region
}

\author{
Keranka Nedeva*, Evgeni Genchev \\ Agricultural University - Plovdiv, Bulgaria, Trakia University - Stara Zagora
}

\begin{abstract}
Keywords:

Economic Growth, Air Transport, Competitive Advantages, Region

\section{Received}

19 May 2018

Received in revised form 20 October 2018

Accepted

23 October 2018

Correspondence: knedeva.au@abv.bg

This study investigates the relationship between the development of the air transport and the economic development of the Bulgarian regions and the improvement of its competitiveness over the period of 2000-2016. The timeliness of the problem is related to the contradictory impact of the air transport on the economic effects of aviation development and related socio-economic effects at local and global level. The purpose of the report was to identify the impact of the air transport on the economic development of the region. In this connection, the following tasks have been set: to monitor trends in the development of the air passenger transport sector; to determine the impact of the average annual income per capita on the passenger flow; to establish the impact of passenger flows on the average annual income of the population as an indicator of the sustainable development of the region. The aim of the article was to establish the link between the passenger flow and the gross domestic product of the region. Economic data processing methods for the 10-year period were used through the Gretl program. The data obtained is evidence of the positive impact of air transport development on the competitiveness of the region and its steady social-economic growth.
\end{abstract}

CAIMI Journals

\section{Introduction}

The timeliness of the problem is related to the contradictory impact of air transport on the economic effects of aviation development and related socio-economic effects at local and global level. The purpose of the present report is to identify the impact of aviation on the sustainable development of the region. In this connection, the following tasks have been set: to monitor trends in the development of the air passenger transport sector, to determine the 
impact of the average annual income per capita on the passenger flow, to establish the impact of passenger flows on the average annual income of the population as an indicator of the sustainable development of the region.

The smoothing of differences and achieving more complete cohesion in its three dimensions - political, economic and social between the enlarged Europe and Bulgaria - the integration of the Bulgarian into the European transport network is a necessary condition for the free movement of goods, people and services, as well as for the economic developing and pooling peripheral and isolated regions with the central parts of Europe. In this regard, there is an increasing credit for air transport.

Aviation is vital for the European economy as it creates jobs, facilitates the trade and links of millions of businesses and citizens with the world. The competitiveness of European aviation, and in particular of international airlines, is seriously threatened. The fastest growing markets are already outside Europe. The European aviation sector - not only airlines, but also aerospace, airports, air traffic management and other services - is facing low growth in the EU and strong global competition. In this regard, the European Commission has prepared an ambitious package of proposals to strengthen the international competitiveness of EU aviation. The main challenges facing the sector are three - shifting growth to other regions of the world, strong international competition (not always loyal) and insufficient investment in airport infrastructure. That is why the European Commission proposes action in three strands - new agreements with neighboring countries and international partners, fair competition and investment. To consult the Member States on the Transport Council, He then plans to take action on these proposals, including drawing up a list of priority issues for the EU to negotiate.

Ever since the onset of aviation, it has become clear that this will lead to a real revolution in transport. Nowadays, this is the fastest way to move goods and people from one point to another. As in the world and in Bulgaria, economic life is directly related to the services provided by air transport. Thus, aviation efficiency has a decisive impact on socio-economic life in our society. The social benefits of aviation are: broadening people's access to new cultures and destinations around the world, improving living standards through tourism, linking hard-to-reach areas and areas covered by social exclusion, contributing to sustainable tourism development, creating economic development, jobs, transport of medicines and organs for transplantation, humanitarian aid. Economic benefits are linked to the importance of world business and tourism for the speed of this type of transport system, with about $52 \%$ of world tourists traveling by air, each dollar invested in airlines having double and triple returns. The household's annual income is one of the most important prerequisites for seeking tourist services that are inevitably related to transport (but its choice largely depends on the country, region, infrastructure, etc.). The effects of the various variables on consumer behavior in air transport are examined in detail by a number of authors.

In recent years, research into the impact of air transport on the sustainable development of the regions has increased. This is understandable given the rapid development of this type of transport. The literature review used includes variety of methods to study the dependency between flight numbers, number of passengers and socio-economic and environmental factors - gross domestic product, income, employment in regions with large airports. 
The impact of airports on regional economic development is particularly pronounced in larger metropolises where the share of workers in culture is higher and hotter areas (Florida, Mellander, \& Holgersson, 2015). Through regression analysis shows that airports contribute significantly to GDP per capita in controlling other variables and that the scope of aerodrome activities is also important.

The efficiency and effectiveness of airlines and their impact on the environment is the subject of a study by a number of authors. $\mathrm{CO} 2$ emissions are a negative or an unwanted result. The quality of airline services is in direct dependence and a positive correlation with the performance and efficiency of airlines (Bitzan, Peoples, \& Wilson, 2016).

The main conclusions of the study on the benefits of air transport are: air transport advances economic and social development, connects people, countries and cultures, gives access to world markets, promotes trade and tourism, creates links between developed and developing countries. Air transport maintains worldwide 58 million jobs, with more than 8.7 million new jobs open over the last three years. The main advantages of this mode of transport are due to the high speed, which results in long distances being traversed for a short time and there is no alternative for urgent movement; speed of service, convenient and efficient services; no investment in infrastructure is required; and, last but not least, the lack of physical barriers and the important role in protecting a given territory. Notwithstanding these and many other advantages, air transport also has some disadvantages: it has a higher degree of risk; it is more expensive - the fastest but also the most expensive transport; the operating costs are higher and include a large part of the costs of airport and airplane construction, investment for the training of trained, experienced and trained staff; less load capacity compared to trains and cargo ships, and higher dependence on meteorological conditions.

The impact of transport infrastructure on territorial economic development: the links between growing intra-regional trade volumes and air traffic in Asia and the Pacific were explored by Van De Vijver, Derudder, and Witlox (2016). They used a heterogeneous analysis of the causal relationship between Granger for the period 1980-2010. They examined the existence of four "causation scenarios" between the different pairs of countries: there is no joint development, which means that both models develop independently (e.g., Japan and Australia); there is "real" co-development, as both models interact with each other through feedback (e.g., South Korea-Philippines); air passenger traffic is facilitated by trade (e.g., South Korea-Philippines); or trade is facilitated by passenger air travel (e.g., AustraliaMalaysia). Certain interpretations of this heterogeneity are proposed.

Air transport has seen phenomenal growth in China over the past 30 years, but there is little research into the development of air transport. The authors, as a result of empirical research, underline that airport development that has a positive impact on economic growth and related economic data and geographic variables (Yu \& Yang, 2008).

Yao and Yang (2008) applied regression analysis to determine the effect of air travel: number of passengers and number of loads and a number of dependent such as: GDP, population density, trade income, employment rate, etc. The authors of this study concluded that economic growth and trade revenues are the main spheres of air transport development as well reveal a negative correlation with the development of inland transport: rail and bus. 
The correlation between airport and economic development is important. Determining a cause-and-effect relationship can be very useful in understanding the economics of the Triangle region as well as other regions around the country and the world. Much of the discussion on the relationship between airport and economic development surrounds four key sub-topics: public finance, economic development, transportation and agglomerate economics, and airports in general. Economic development is often linked with infrastructure development, which means that airports are expected to further the development of the economies of the surrounding regions. Transportation, in general, affects the development of cities, with air travel having a large stake in both short and long distance transportation.

The decrease in the cost of the transportation of both passengers and freight in air transport leads the increase of its accessibility. In this concept, when a region has an active airport it helps to increase the region's competitiveness and support its economic, social and cultural development (Baltaci, Sekmen, \& Akbulut, 2015).

Florida, Mellander, and Holgersson (2015) examined the role of airports in regional development. Based on multiple regression analysis, their research generated findings that airports add significantly to regional development measured as economic output per capita.

Van de Vijver, Derudder, and Witlox (2016) scrutinized the mutual and complex causal relationship between air passenger transport and regional development in the European NUTS2-regions. Using the Granger analysis, they confirmed Irwin and Kasarda's findings that 'changes in air transportation have altered the competitive advantages of metropolitan areas, and not the reverse".

Baltaci, Sekmen, and Akbulut (2015) analyzed whether an active airport and its traffic frequency have an effect on country's macroeconomic indicators. In this study, region-fixed effect and two stage least square (2SLS) models were applied with using panel data for 26 sub-regions at NUTS 2 level in Turkey period of 2004-2011. The results of this study supported that increasing in number of active airports and its traffic frequency has a positive effect on regional economic growth.

Profillidis and Botzoris (2015) used econometric models and analyzed whether a correlation exists between air passenger transport and economic activity at world level and for the various geographical areas of the world. The whole analysis permits an estimation of a plausible evolution of air passenger transport activity and of its growth rates that can be expected.

Hakim and Merkert (2016) examined causal relationships between aviation and economic growth in South Asia. Their results showed long-run uni-directional causality running from GDP to air transport. Country specific Time Series Cross Section (TSCS) tests confirmed their causality results.

Scientists at the University of Oxford have conducted a sociological study to determine what the social and economic benefits of air travel are. Some of the most interesting lessons learned from Oxford are: air transport advances economic and social development, favors and supports trade and tourism, opens up new jobs. Aviation provides the world's only fastmoving transport system, making it vital to global business and tourism, airline shares have double and triple returns. Aviation expands people's access to new cultures and destinations around the world, contributes to the sustainable development of tourism and trade in goods, 
improves living standards and combats poverty through tourism, sometimes serves as the only means of transport to areas that are difficult accessed or covered by social exclusion. It generates economic development.

\section{Method}

The object of this survey are the NUTS 2 regions in Bulgaria - Southwest, Northeast and Southeast, where the three largest airports with international flights (Sofia, Varna and Burgas airports) are located. The purpose of it is to reveal the relationship between the passenger flow and the average annual income of the population in these regions.

For the purpose of the analysis, two indicators were used and their dependencies and ratios - passenger flow and average annual income of the population. The subject of the study is three regions at NUTS 2 level, respectively. The three regional districts (NUTS3) in which are located the biggest airports with international flights in Bulgaria (Sofia, Varna and Burgas airports). The study period was 12 years (2004-2016). Data sources were the airport administrations, the NSI (www.nsi.bg, National Statistical Institute), the Civil Aviation Directorate General Directorate (DG CAA) (www.caa.bg/bg, Directorate general "Civil Aviation Administration"). Data processing was with Microsoft Excel and GRETL econometric software.

Hsiao (2003) and Wooldridge (2001) pinpointed some of the key benefits of panel data models. Firstly, in the use of panel data, a large number of independent observations are obtained - if spatial regression has a number of observations equal to $\mathrm{N}$ (number of units), and for time $\mathrm{T}$ (number of periods), the panel data includes $\mathrm{N} * \mathrm{~T}$ points with data. This increases degrees of freedom and in theory should lead to better statistical dependence.

Typically, in the literature, the panels can be divided into two groups depending on the relationship between the number of objects examined $(\mathrm{N})$ and the number of periods $(\mathrm{T})$. Macro panels are characterized by a relatively large number of observations and a small number of objects. Micro panels back are used for a large number of objects and a relatively small number of time periods. This panel uses panel data of the first type, i.e., macropanel.

There are two main classes of panel techniques: the fixed effects model and the random effects model. It is considered that the random effect model is more appropriate when the units were randomly selected and the fixed effect model is more appropriate when the units represent substantially the whole set. Given that, over $90 \%$ of all flights account for more than $90 \%$ of all flights, it is justified to use the fixed effect model.

\section{Results and Discussion}

For the purpose of the analysis, we used passengers flow data collected from the three largest airports in Bulgaria (Sofia, Varna and Bourgas airports) for the 2004-2016 period and the average annual income of the population in the regions where they are located - Southwest, Northeast and Southeast.

The random effect model is considered better when the units were randomly selected and the fixed effect model is more appropriate when we look at the units as a whole set. Given that, the flights from the selected airports represent $90 \%$ of all the flights in the country and it is best fitting to use the fixed effect model. For panel processing, we used data from a total of 
39 observations - (3 units $\times 12$ periods). A second check was made to select the model (fixed/random effect) using the Hausman test.

The airport's overall infrastructure is well developed. Bulgaria has five operating airports for public use, three non-operating airports and a number of airfields - Sofia, Varna, Bourgas, Plovdiv, Gorna Oryahovitsa and about 150 airfields for the needs of agricultural aviation. Rousse and Stara Zagora (independent commercial companies) and Targovishte (registered in the capital of Bourgas airport) are not operating at the present. The projected increase in passenger traffic in the five airports is about $85 \%$ by 2020 .

The main function of the airports in Bulgaria is to serve the international passenger traffic to and from the country. In practice, the role of air transport in domestic passenger and cargo flights is negligible. The major challenges for Bulgarian airports stem from, on the one hand, increasing traffic and, on the other hand, its uneven distribution.

Importantly for the future operation and development of Bulgarian airports, which, except for those in Varna and Burgas, are operated by state operators, is to find private investors to be linked to their maintenance and long-term development. Experience shows that this will be a great challenge as Bulgarian airports are not attractive to investors. For development of the transport infrastructure through the mechanisms of the concession in the air transport sector, Rousse, Gorna Oryahovitsa, Stara Zagora, cargo terminal Plovdiv airport and Plovdiv airport are envisaged for concession.

The location of the airports and the liberalization of Bulgaria's economic relations with the EU countries provide many opportunities for turning Bulgarian airports into modern transport centers that generate additional economic activity. The vast majority of them are located along corridors of the trans-European transport network and are close to tourist or industrial centers.

For 2017, 11.4 million passengers have passed through Bulgarian airports. There was an increase of $18.1 \%$ of the passengers transported on international flights from and to Bulgaria. The growth for Sofia Airport is $29.1 \%$ and for Varna and Burgas a total of $6 \%$. The growth is due to the participation of low-cost carriers, none of the traditional carriers has reduced their flights.

For the year 2018, the figures are expected to be even better. Rates between 5\% and 15\% have already been recorded for early flights with flights to Varna and Burgas, and in January 2018 the capital served a total of 499,688 passengers, a $6.6 \%$ increase over the same period in 2017.

The main driver of this traffic is the low airfare prices. Not only tourism, but also business trips in various economic sectors as well as opportunities for more frequent trips of Bulgarians have increased. 


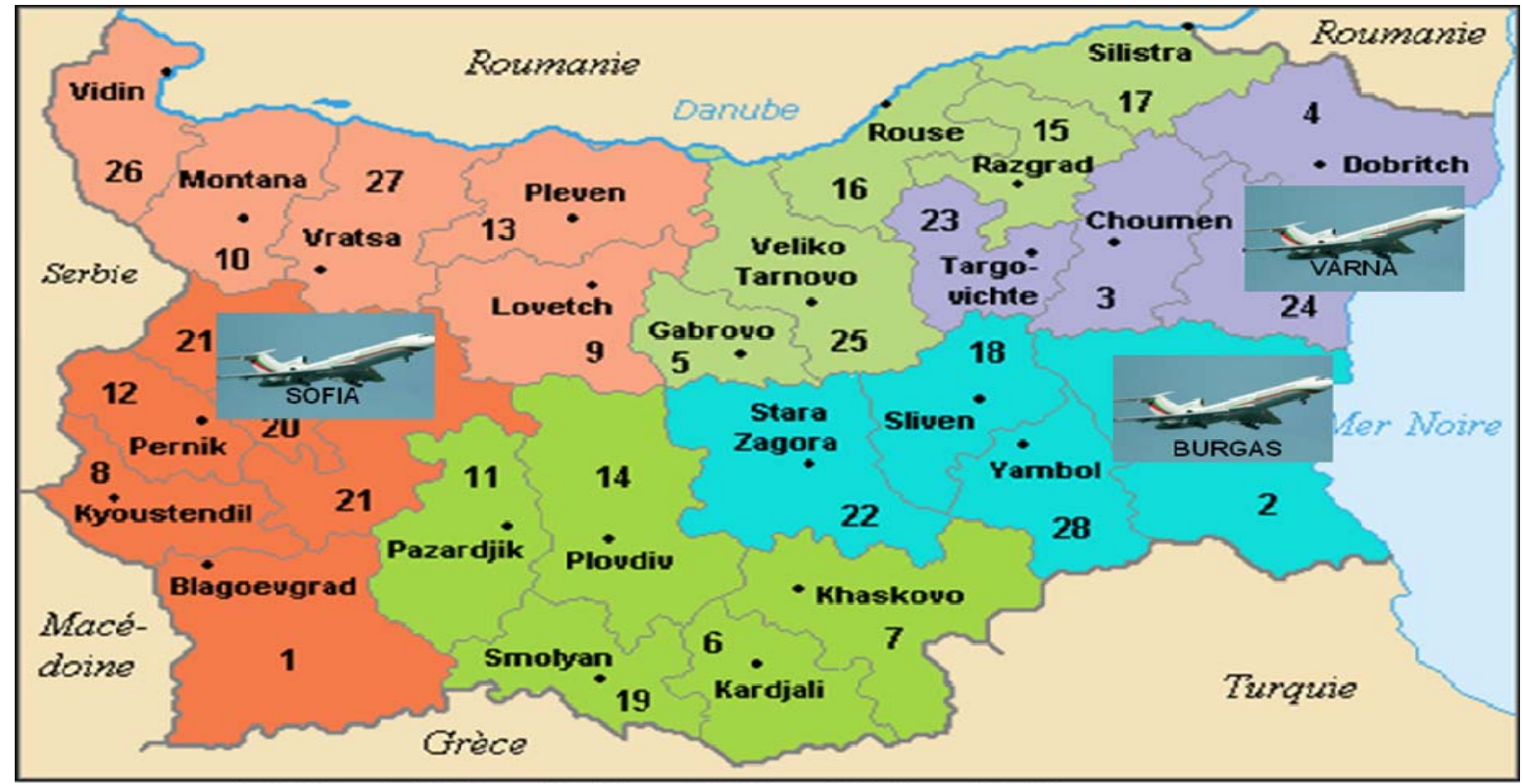

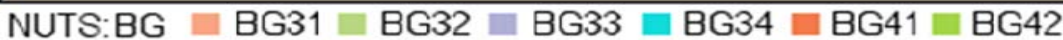

Figure 1. Passengers, Crossing International Airports in Bulgaria, Number

Sofia Airport has the potential to become one of the biggest and most modern airports in the Balkans. For 2017, the number of passengers arrives at a record of 6 million. At Terminal 2 , it has passed $65 \%$ of the passenger flow, and 35\% remaining through Terminal 1 . The metropolitan airport occupies first place for the fastest growing traffic in the category of 3 to 5 million passengers. The record-breaking 22\% increase in the number of people traveled in 2016 overtakes another excellent Krakow airport - the Polish one in Krakow, which is why Sofia airport is distinguished by the world-known online aviation news and analysis "anna.aero".

In 2016, Bourgas Airport serves a record number of passengers, nearly 2,900,000, and occupies the second place for the busiest airport in the country. In 2017, Burgas airport surpassed its record number of passengers and welcomed 3,000,000 at the end of the year. Significant growth is also reported for the inland traffic due to the higher frequency of flights on the Burgas-Sofia route. The airport has a 3200-meter runway, operates 24 hours without interruption, more than 20,000 flights in 2016, more than 2.8 million passengers in 2016, and more than 140 destinations in over 75 countries.

Varna Airport serves northeastern Bulgaria and provides convenient connections with major airports such as Sofia, Vienna, Istanbul, Moscow, and Belgrade. Varna Airport is situated on the coast of the northern Black Sea coast, $8 \mathrm{~km}$. from Varna. The town is a major tourist destination, starting point near all the resorts in the northern part of the Bulgarian Black Sea coast. Varna is an important business and university center, a port and headquarters of the Bulgarian Navy. The favorable geographic position, the combination of air, sea, rail and car transport allow for intermodal connections, allow for a large number of charter flights during the summer season and regular flights throughout the year. Varna Airport has a huge contribution to the development of the transport network, tourism and trade in the region. It has a runway of 2500 meters, operates 24 hours without slots, performed nearly 15,000 aircrafts in 2016, 1.7 million passengers in 2016 in 102 destinations. 
The analysis on passenger flows and income on average per person gives ground to seek a link between the efficiency of air transport and its contribution to the development of the economy of the region and the country. There is an increasing trend of passenger traffic at all three airports, especially fast at Bourgas airport (Figure 1).

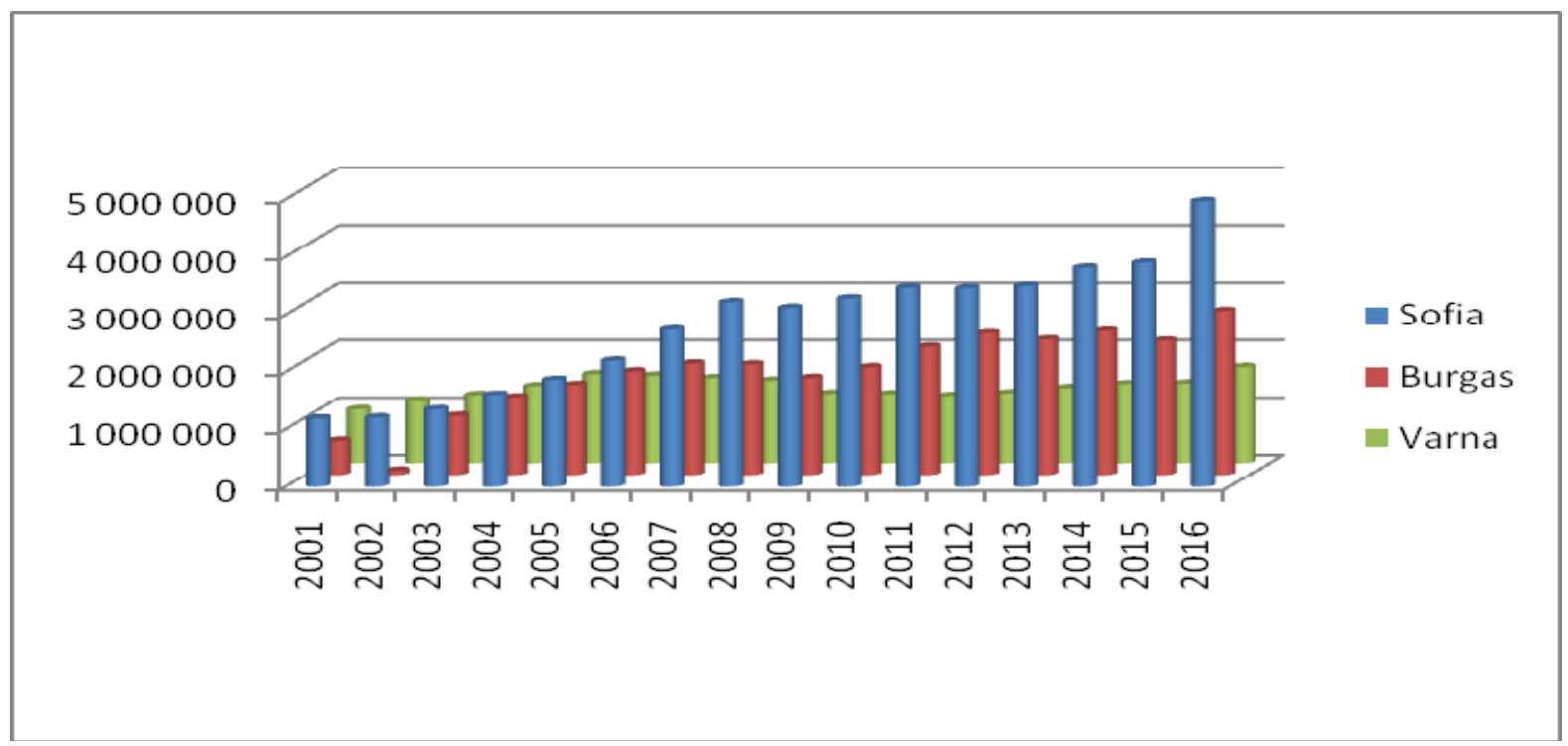

Figure 1. Passengers, Crossing International Airports in Bulgaria (Number) Source: NSI

The same trend is seen in the income of the population and GDP (Figure 2,3)

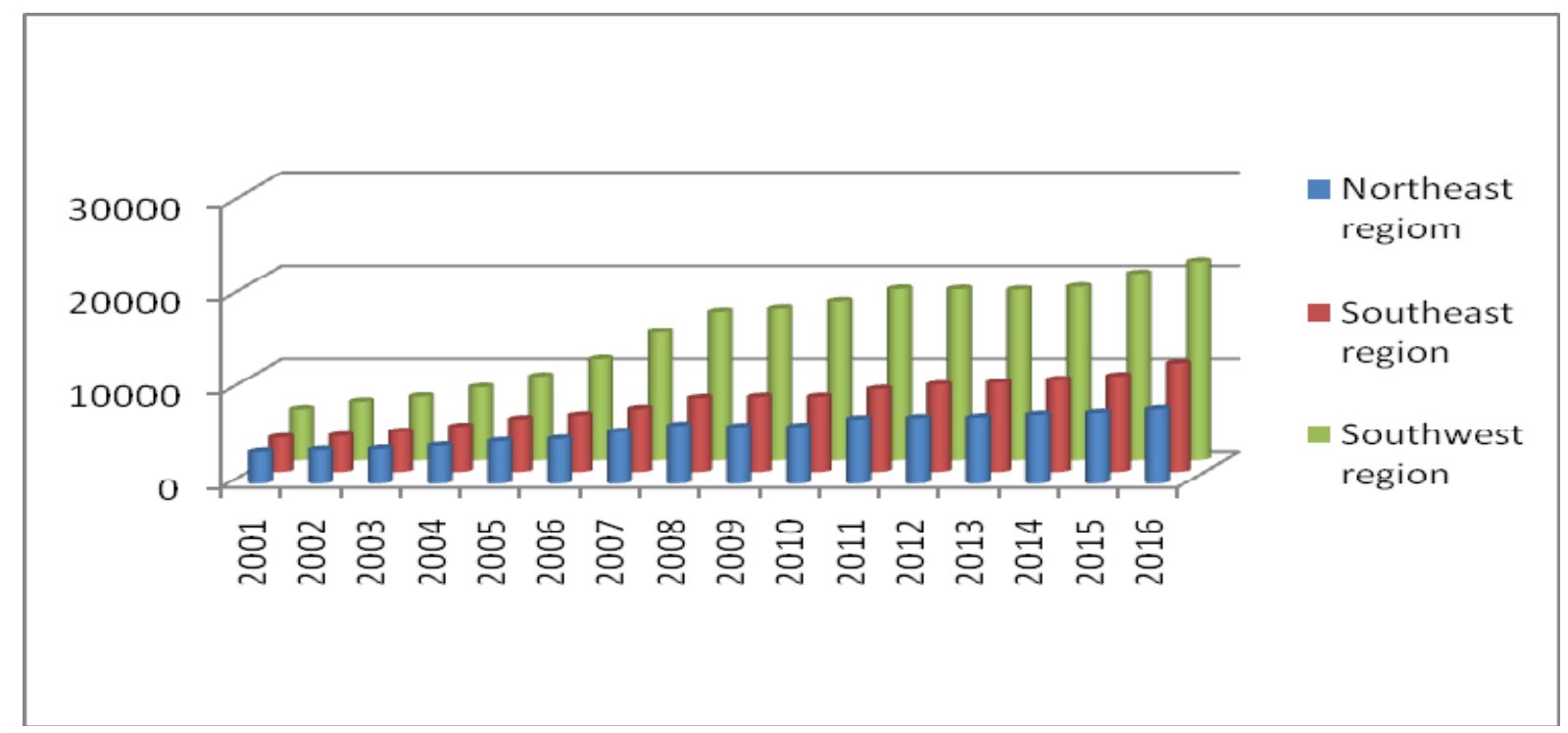

Figure 2. GDP per Capita, BGN

Source: NSI

Figure 3 shows that the average annual per capita personal income trend is going steady up. The distribution of income shows the clearly rising role of the capital based on the the area where most of the income in the Bulgarian economy is generated. Sofia district 
respectively WSR shows a significant growth of gross domestic product per capita, and the increase in wages and incomes in the area also leads to improvement of the living conditions.

Gross domestic product per capita growth in the district of Varna is lower than the average for the country, Varna has remained below the average income for the country for the first time since 2013.

Prior to the crisis, the Bourgas region's economy is developing at a rapid pace, and in 2005 and 2006 the GDP per person of the district even exceeded the country average, the average annual household income also increased.

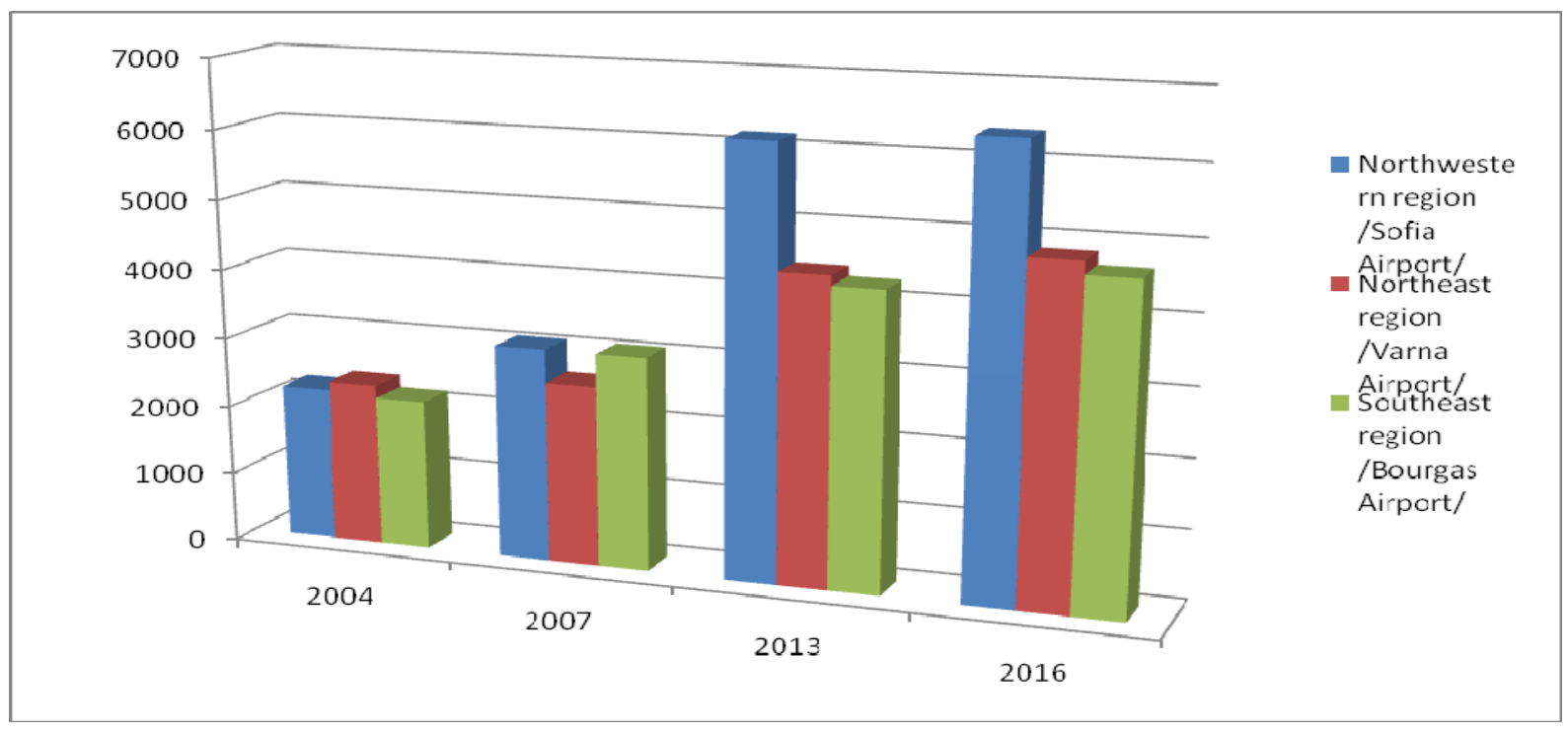

Figure 3. Average Income per Person by Region NUTS 2 / BGN / Source: NSI

Figure 3 shows that the average annual per capita personal income trend is going steady up with the Northeast region having a slight lead compared to the Southeast where the Bourgas airport is located, the second biggest airport in Bulgaria. This is because of the variety of factors, making greater impact on the air transport passenger revenue.

\section{Effect of the Income of the Population on the Passenger Flow}

We used the panel data model to measure the effect of the air transport on the present study. We collected all the observation data on all air ports in one general regression.

The equation of the common panel data model looks like this:

$\mathrm{Y}$ it $=a+\beta * x$ it where: $a$ and $\beta$ - regression parameters,

$\mathrm{Y}$ it - the value of the dependent variable number of trips for airport $i$ in period $t$,

$x$ it - value of the independent variable income for a passenger from region $i$ in period $t$.

The dependent variable is the number of passengers, and the independent (predictor) variable is the average annual income of the population for the respective region of the country. For panel processing we used data from a total of 39 observations - ( 3 units x 13 
periods). A second check was made to select the model (fixed / random effect) using the Hausman test (1978).

$$
\mathrm{H}=0.954, \mathrm{p} \text {-value }=\operatorname{prob}(\operatorname{prob}(\mathrm{X} \text {-square }(1)>0.95)=0.328585
$$

In the case of a low p-value, there is a reason to reject the hypothesis that the randomaction model is more appropriate than a fixed-effect model. Two variants of the model are considered with the values of the variables themselves and their natural logarithms (Table 1 and 2).

Table 1

Effect of Total Number of Passengers on Income in the Region Fixed Effect, Values of the Variable

\begin{tabular}{lcccc}
\hline Independent variables & Coefficient & $S E$ & $t$ & $p$ \\
\hline Constant & -191277 & 130276 & -1.46 & .151 \\
Log Annual income & 75.62 & 29.77 & 2.54 & $.01^{* *}$ \\
\hline Note: $* *$ level of significance $<.05$ & & & &
\end{tabular}

Table 2

Effect of Total Number of Passengers on Income in the Region Fixed Effect, Natural Logarithms of the Variables

\begin{tabular}{lcccc}
\hline Independent variables & Coefficient & $S E$ & $t$ & $p$ \\
\hline Constant & -6.21 & 3.43 & -1.81 & $.07^{*}$ \\
Log Annual income & 2.07 & .41 & 5.02 & 1.50 \\
\hline Note: * level of significance $<.10 ; * * *$ level of significance $<.01$ & & &
\end{tabular}

\section{Conclusion}

The results from the two types of econometric model show that there is a statistically significant correlation between the passenger flow from air transport and the average annual per capita income as an indicator of the economic development of the region. It is evident that in the first variant the constant is not significant and it is statistically significant in the second. In this case, however, more important is the effect of the total number of passengers on the income of the population, which can be said to be of very high statistical significance (8.70e-09*** / 3.40e-07***). The results of this study are summarized as following:

- The impact of the income on the passenger flow is greater but with less statistical importance.

- The impact of the passengers' flow on the population is low but with bigger statistical significance.

- Although slowly, the air transport has a great effect on the sustainable development of the region.

- Airports add significantly to regional development measured as economic output per capita and varies with their size and scale.

The following conclusions can be drawn: the influence of the incomes on the passenger flow is stronger but has less statistical significance, whereas the impact of the passenger flow on the income of the population is weak (.002), but statistically meaningful, with a lasting 
and prolonged manifestation, i.e., air transport, and albeit slow, but has a significant impact on the sustainable development of the region in its socio-economic dimensions.

Further research is required to examine the links between air transport with other indicators such as employment, economic growth, economic effects and local environmental results. It is suggested to conduct a research in the future to explore the role of air transport in the socio-economic development of the regions.

\section{References}

Baltaci, N., Sekmen, O, \& Akbulut, G. (2015). The relationship between air transport and economic growth in turkey: Crossregional panel data analysis approach. Journal of Economics and Behavioral Studies, 7(1), 89-100.

Bitzan, J. D., Peoples, J. H., \& Wilson, W. W. (Eds.). (2016). Airline efficiency. United Kingdom: Emerald Group Publishing.

Florida, R., Mellander, C., \& Holgersson, T. (2015). Up in the air: the role of airports for regional economic development. The Annals of Regional Science, 54(1), 197-214.

Hakim, M. M., \& Merkert, R. (2016). The causal relationship between air transport and economic growth: Empirical evidence from South Asia. Journal of Air Transport Management, 56, 120-127.

Hausman, J. A. (1978). Specification tests in econometrics. Econometrica, 46(6), 1251-1271.

Hsiao, C., (2003). Analysis of panel data, 2nd edition. Cambridge: Cambridge Universirty Press.

Profillidis, V., \& Botzoris, G. (2015). Air passenger transport and economic activity. Journal of Air Transport Management, 49, 23-27.

Van de Vijver, E., Derudder, B., \& Witlox, F. (2016). Air passenger transport and regional development: Cause and effect in Europe. Promet-Traffic and Transportation, 28(2), 143-154.

Wooldridge J. M. (2001). Econometric analysis of cross section and panel data. United Status: The MIT Press.

Yao, S., \& Yang, X. (2008). Airport development and regional economic growth in China. Nottingham, UK: University of Nottingham. 